\title{
RELATING ABILITY AND PERSONALITY TO THE EFFICACY AND PERFORMANCE OF DYADIC TEAMS
}

\author{
Eric Anthony Day \\ University of Oklahoma \\ Bryan D. Edwards \\ Texas A\&M University
}

\author{
Winfred Arthur, Jr. \\ Texas A\&M University \\ Suzanne T. Bell \\ Texas A\&M University
}

\begin{abstract}
We examined the extent to which member ability and personality relate to differences in team performance and team efficacy in a task setting that simulated the high degree of role interdependence and humantechnology interaction found in many military contexts. 168 male participants were assigned to dyadic teams and trained for two weeks to learn and perform a complex computer task that simulated the demands of a dynamic aviation environment. Participants also completed measures of general mental ability, psychomotor ability, and the Big Five personality traits (extraversion, openness, conscientiousness, agreeableness, and emotional stability). Team performance and team efficacy were assessed multiple times throughout training. Results indicated that ability was a critical determinant of both performance and efficacy, and personality traits yielded an incremental contribution to both performance and efficacy. In particular, psychomotor ability and conscientiousness were the strongest and most consistent factors associated with team effectiveness.
\end{abstract}

With the proliferation of teams in organizations, including the military (Guzzo \& Dickson, 1996; Salas, Bowers, \& Cannon-Bowers, 1995), there has been a concurrent interest in identifying the determinants of team effectiveness. For instance, researchers have acknowledged the potential influence of individual differences on learning and performance in team settings (Driskell, Hogan, \& Salas, 1987; Hackman, 1987). However, with the exception of a few studies, little empirical attention has been paid to selection into teams and corresponding optimal team compositions. Therefore, our purpose was to examine the extent to which member ability and personality relate to differences in team performance in a task setting that simulated the high degree of role interdependence and human-technology interaction found in many military contexts. In addition to performance, we also included team efficacy as a measure of team effectiveness. Not only is efficacy an important determinant of individual and team task performance, efficacy can also be considered an indicator of a team's long-term viability and ability to adapt to novel challenges (Bandura, 1997; Gully, Incalcaterra, Joshi, \& Beaubien, 2002).

In examining models of team effectiveness, research suggests that task considerations moderate the extent to which human characteristics are predictive of team performance. For example, researchers like Barrick, Stewart, Neubert, and Mount (1998) and Neuman and Wright (1999) have invoked Steiner's (1972) taxonomy of group tasks and investigated the extent to which different team-level operationalizations (i.e., mean, minimum, maximum, and variance of team members' scores) of general mental ability (GMA) and the Big Five personality traits (extraversion, openness, conscientiousness, agreeableness, and emotional stability) are related to team effectiveness. Although studies have consistently demonstrated that GMA is a useful predictor of team performance (Devine \& Philips, 2001), results regarding personality traits and other team criteria have been equivocal. Consistent with previous discussions of task considertions (e.g., McGrath, 1984; Steiner, 1972), one could argue that the mixed results may be due to the different types of teams and tasks under investigation. For instance, Barrick et al. (1998) studied teams from manufacturing facilities, and Neuman and Wright (1999) studied human resource representatives in retail stores. Furthermore, neither the teams in these studies nor the teams in other studies of personality determinants of team performance exhibited the high-levels of role interdependence and human-technology interaction found in military crews.

Indeed, researchers have indicated that role interdependence and human-technology interactions warrant close examination when considering the nature of teams in many military settings (Cannon-Bowers, Salas, \& Blickensderfer, 1998; Tziner \& Eden, 1985). Members of military crews frequently perform their task duties simultaneously in close synchronization with one another. Moreover, the high degree of interaction with technology found in military crews provides well-defined mechanisms for performing task responsibilities (McGrath, Berdahl, \& Arrow, 1995). Member roles and contributions are highly specific and constrained by technological demands.

Given that human-technology interactions and interdependence are important team characteristics and few studies of team composition effects have involved teams with high levels of both characteristics, we sought to extend the literature by examining the extent to which member ability and personality relate to differences in team efficacy and performance in a context that involves a high degree of human-technology interaction and interdependence between task components. Additionally, we also examined different methods for operationalizing team-level ability and personality (mean, maximum, minimum, and range of team members' scores). Specifically, the following questions were examined:

1. To what extent do GMA, psychomotor ability, and the Big Five personality traits predict efficacy and perrormance in dyadic teams? 
2. Does the personality of team members explain a significant proportion of team efficacy and performance beyond that explained by team ability?

3. Do different operationalizations of team ability and personality (mean, maximum, minimum, and difference between maximum and minimum) have different relationships with efficacy and performance?

\section{METHOD}

\section{Participants}

Participants were 194 young adult males from a large southwestern university and its local community. Participants were randomly assigned to dyadic teams. Eighty-four teams completed the study. Participants who completed the study were paid $\$ 75$. Participants also competed for bonuses of $\$ 100, \$ 60$, and $\$ 40$ awarded to the top three performing teams.

\section{Materials}

We measured GMA using the Raven's Advanced Progressive Matrices (Raven, Raven, \& Court, 1994). We measured psychomotor ability using an aiming task that tests the speed and accuracy with which individuals can aim and hit targets using a joystick (Gopher, Weil, \& Siegel, 1989). The Big Five personality traits were assessed using Goldberg's 100 Unipolar Markers (Goldberg, 1992). We used the video game Space Fortress (SF; Mane \& Donchin, 1989) as our performance task. SF includes important informationprocessing and psychomotor demands that are present in aviation and other complex tasks (Gopher, Weil, \& Bareket, 1994; Hart \& Battiste, 1992). We measured team efficacy by averaging the responses from two paper-and-pencil items ("How confident are you in the ability of your team to play Space Fortress?" and "If your team played Space Fortress in competition with 10 other teams, how do you think your team will place?").

\section{Procedure}

Table 1 provides a summary of the training procedures. Participation consisted of one pre-training session and 10 days of training held Monday through Friday for two consecutive weeks. Pre-training involved the assessments of GMA, personality, and psychomotor ability. Day 1 of training consisted of videotaped instructions, two 3-minute baseline SF games (session 0), and a videotaped summary of instructions. Thereafter, trainees underwent $11 \mathrm{SF}$ training sessions over the rest of the two-week period.

During a standard training session, teams performed six practice games followed by two test games. All games lasted three minutes. Teams performed with one trainee controlling all functions related to the mouse controls (copilot minemissile manager) using his left hand and the other trainee controlling all functions related to the joystick and trigger controls (pilot-gunner) using his right hand. Trainees alternated roles at the end of each game. Communication between trainees was encouraged. For each session, performance was operationalized as the mean of scores from the two test games. The efficacy measure was completed at the end of sessions 1,3 , and 9 .

Table 1

Overview of Training and Data Collection Procedures

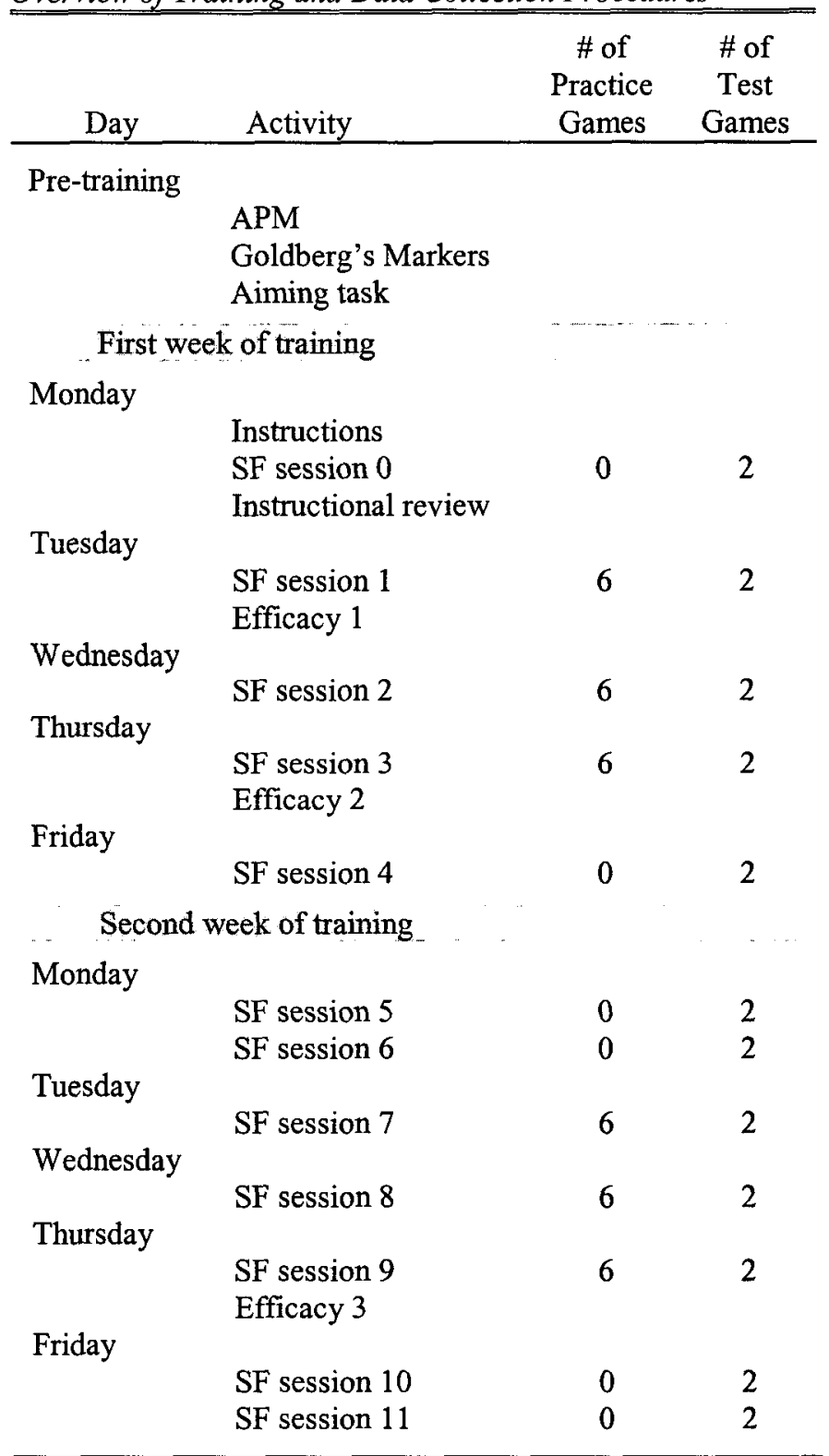

$\overline{\text { Note. } \mathrm{APM}=\text { Advanced Progressive Matrices. } \mathrm{SF}=\text { Space }}$ Fortress.

\section{RESULTS}

Correlations between the different team composition variables (GMA, psychomotor ability, and personality) across the different operationalization methods (mean, minimum, 
Table 2

Means, Standard Deviations, and Correlations for Team Performance and Team Efficacy

\begin{tabular}{|c|c|c|c|c|c|c|c|c|}
\hline Variable & $M$ & $S D$ & 1 & 2 & 3 & 4 & 5 & 6 \\
\hline 1. SF block 1 & -751.39 & 830.71 & --- & & & & & \\
\hline 2. SF block 2 & 1547.82 & 1415.50 & .75 & --- & & & & \\
\hline 3. SF block 3 & 2793.57 & 1612.73 & .70 & .91 & --- & & & \\
\hline 4. SF block 4 & 3543.49 & 1688.93 & .61 & .82 & .95 & --- & & \\
\hline 5. Efficacy 1 & 7.29 & 1.34 & .31 & .50 & .49 & .43 & $\cdots$ & \\
\hline 6. Efficacy 2 & 7.72 & 1.37 & .32 & .54 & .54 & .44 & .84 & --. \\
\hline 7. Efficacy 3 & 8.24 & 1.35 & .27 & .49 & .57 & .56 & .61 & .67 \\
\hline
\end{tabular}

Note. SF $=$ Space Fortress. SF block $1=$ mean of SF sessions 0 and 1. SF block $2=$ mean of SF sessions 2 and 3. SF block $3=$ mean of SF sessions 4 through 9 . SF block $4=$ mean of SF sessions 10 and 11 . If $r>|.21|$, then $p<.05$; if $r>|.27|$, then $p<.01$; if $r>|.34|$, then $p<.001 . N=84$. All tests are two-tailed.

maximum, and range) were first examined. The results indicated that the mean scores for each variable were highly correlated with the maximum and minimum scores, suggesting redundancy between the mean method and the maximum and minimum methods. Although the maximum and minimum scores were moderately intercorrelated, it appears that these two methods may operationalize team-level characteristics differently. As shown in Table 2, team performance and efficacy were moderately to strongly intercorrelated.

Table 3 shows the correlations between the team composition variables, team performance, and team efficacy. As shown, the mean, minimum, and maximum scores for GMA and psychomotor ability yielded moderate to strong correlations with performance. In contrast, correlations for the personality scores were generally weak, although the minimum and range scores for conscientiousness and the range scores for emotional stability yielded moderate correlations with performance. With respect to team efficacy, GMA did not yield statistically significant correlations, but both the minimum and range scores for psychomotor ability were significantly correlated with team efficacy. Of the personality variables, only the maximum scores for openness, conscientiousness, and emotional stability yielded statistically significant correlations with team efficacy.

To further investigate the roles of member ability and personality, we used hierarchical regression to assess the incremental validity of personality over that of ability in regard to team performance and efficacy. Specifically, we first examined a model that included ability-based composition variables as predictors. Next, we examined a second model that included both ability-based and personality-based composition variables as predictors. Only those composition variables that yielded consistently significant zero-order correlations with performance and efficacy were included. Also, because the mean scores yielded a high degree of multicollinearity with the minimum and maximum scores, we did not include mean scores in these analyses. We used the mean team performance and efficacy scores across the training sessions as criteria. Separate analyses were conducted for performance and efficacy.
As shown in Table 4, GMA and psychomotor ability accounted for a substantial proportion of the variance in team performance $(46 \%)$. Specifically, minimum scores for GMA and psychomotor ability yielded statistically significant regression coefficients. After controlling for ability, personality accounted for an additional $10 \%$ of the variance in performance. Only the range scores for conscientiousness yielded a statistically significant regression coefficient. The positive regression weight indicates that variability in conscientiousness scores was associated with higher levels of team performance. Relative to performance, ability-based variables accounted for a smaller but statistically significant proportion of variance $(13 \%)$ in team efficacy. Only the minimum scores for psychomotor ability yielded a statistically significant regression coefficient. Personality accounted for an additional $11 \%$ of the variance, with maximum scores for conscientiousness and emotional stability yielding statistically significant regression coefficients.

\section{DISCUSSION}

The results of this study indicated that ability was a critical determinant of both team performance and team efficacy, and personality traits yielded an incremental contribution to both performance and efficacy. However, ability made a substantially greater contribution to team performance compared to personality traits. These findings contribute to the vast literature that emphasizes the strong connection between ability and performance. Additionally, results indicated that the relationships between ability, personality, and team effectiveness varied depending on the team-level operationalization of the ability and personality variables. Specifically, the teams' minimum ability scores, particularly for psychomotor ability, were more strongly associated with team effectiveness than either the maximum or range of ability scores. In contrast, range scores for conscientiousness and maximum scores for conscientiousness and emotional stability were more strongly associated with team effectiveness than minimum scores. Although both the maximum and minimum scores were highly correlated with 
Table 3

Correlations between Team Composition Variables and Team Performance and Team Efficacy

\begin{tabular}{|c|c|c|c|c|c|c|c|}
\hline Variable & $\begin{array}{c}\text { SF } \\
\text { block } 1\end{array}$ & $\begin{array}{c}\text { SF } \\
\text { block } 2\end{array}$ & $\begin{array}{c}\text { SF } \\
\text { block } 3\end{array}$ & $\begin{array}{c}\text { SF } \\
\text { block } 4\end{array}$ & Efficacy 1 & Efficacy 2 & Efficacy 3 \\
\hline \multicolumn{8}{|l|}{ GMA } \\
\hline 1. mean & .40 & .52 & .53 & .50 & .14 & .10 & .12 \\
\hline 2. minimum & .40 & .48 & .50 & .45 & .13 & .13 & .09 \\
\hline 3. maximum & .30 & .44 & .44 & .43 & .11 & .04 & .13 \\
\hline 4. range & -.14 & -.08 & -.11 & -.07 & -.04 & -.11 & .04 \\
\hline \multicolumn{8}{|l|}{$\begin{array}{l}\text { Psychomotor } \\
\text { ability }\end{array}$} \\
\hline 5. mean & .60 & .51 & .53 & .49 & .28 & .20 & .17 \\
\hline 6. minimum & .58 & .52 & .53 & .50 & .34 & .30 & .28 \\
\hline 7. maximum & .50 & .40 & .42 & .39 & .18 & .08 & .05 \\
\hline 8. range & .02 & -.04 & -.03 & -.03 & -.13 & -.21 & -.23 \\
\hline \multicolumn{8}{|l|}{ Extraversion } \\
\hline 9. mean & -.06 & .05 & .02 & .04 & .19 & .19 & .16 \\
\hline 10. minimum & .03 & .09 & .05 & .04 & .14 & .20 & .21 \\
\hline 11. maximum & -.13 & -.02 & -.02 & .02 & .19 & .10 & .05 \\
\hline 12. range & -.14 & -.10 & -.06 & -.02 & .04 & -.10 & -.15 \\
\hline \multicolumn{8}{|l|}{ Openness } \\
\hline 13. mean & .12 & .21 & .17 & .19 & .24 & .24 & .10 \\
\hline 14. minimum & .10 & .17 & .15 & .19 & .18 & .18 & .04 \\
\hline 15. maximum & .10 & .17 & .12 & .12 & .23 & .22 & .13 \\
\hline 16. range & -.02 & -.03 & -.05 & -.09 & .01 & .01 & .06 \\
\hline \multicolumn{8}{|l|}{ Conscientiousness } \\
\hline 17. mean & -.15 & -.07 & -.06 & -.01 & .08 & .13 & .14 \\
\hline 18. minimum & -.26 & -.23 & -.23 & -.19 & -.06 & .06 & .01 \\
\hline 19. maximum & .03 & .15 & .15 & .19 & .22 & .17 & .24 \\
\hline 20. range & .27 & .35 & .35 & .34 & .24 & .09 & .19 \\
\hline \multicolumn{8}{|l|}{ Agreeableness } \\
\hline 21. mean & -.05 & -.10 & -.13 & -.08 & .00 & .05 & .00 \\
\hline 22. minimum & -.08 & -.13 & -.12 & -.08 & .02 & .05 & -.10 \\
\hline 23. maximum & .00 & -.04 & -.11 & -.05 & -.03 & .03 & .11 \\
\hline 24. range & .08 & .10 & .02 & .03 & -.05 & -.02 & .20 \\
\hline \multicolumn{8}{|c|}{ Emotional stability } \\
\hline 25. mean & .06 & .12 & .16 & .20 & .23 & .17 & .24 \\
\hline 26. minimum & .07 & .03 & .00 & .02 & .17 & .09 & .12 \\
\hline 27. maximum & .16 & .22 & .27 & .30 & .21 & .20 & .29 \\
\hline 28 . range & .22 & .24 & .26 & .27 & .05 & .11 & .17 \\
\hline
\end{tabular}

Note. $\mathrm{SF}=$ Space Fortress. GMA = general mental ability. SF block $1=$ mean of SF sessions 0 and 1. SF block $2=$ mean of SF sessions 2 and 3. SF block $3=$ mean of SF sessions 4 through 9 . SF block $4=$ mean of SF sessions 10 and 11. If $r>|.27|$, then $p<.05$; if $r>|.27|$, then $p<.01$; if $r>|.34|$, then $p<.001$. $N=84$. All tests are two-tailed.

the mean scores, our results suggest the maximum and minimum scores are meaningfully different from each other and range scores.

The finding that personality modestly contributed to team performance is consistent with meta-analyses of the Big Five and individual performance (Hurtz \& Donovan, 2000). The modest correlations for personality are also consistent with the fact that many team tasks have technological constraints that obviate the need for interpersonal interactions by limiting team members' discretion in structuring their roles (Cannon-
Bowers et al., 1998). In contrast, when team members are not limited by technological constraints, members have substantial leeway in structuring their roles and tasks. In such cases, members must interact more to determine how they should function together. Consequently, personality traits like agreeableness and extraversion may contribute more to team effectiveness.

In conclusion, the present findings suggest that ability and to a smaller extent personality are both related to the effectiveness of teams whose members have highly 
Table 4

Summary of Regression Analyses

\begin{tabular}{|c|c|c|c|c|}
\hline Model & $\beta_{1}$ & $\beta_{2}$ & $R^{2 \mathrm{a}}$ & $\Delta R^{2 \mathrm{~b}}$ \\
\hline \multicolumn{5}{|l|}{$\begin{array}{l}\text { Team } \\
\text { performance } \\
\text { 1.Ability }\end{array}$} \\
\hline GMA min & $.28 * *$ & $.26 * *$ & & \\
\hline GMA $\max$ & $.17 \dagger$ & .14 & & \\
\hline PSYMOT min & $.42^{* * *}$ & $.38 * * *$ & & \\
\hline PSYMOT max & .03 & .06 & $.46^{* * *}$ & \\
\hline \multicolumn{5}{|l|}{ 2.Personality } \\
\hline CONSC min & --- & .08 & & \\
\hline CONSC range & --- & $.34 * *$ & & \\
\hline EMOTI range & -- & .11 & $.56^{* * *}$ & $.10^{* *}$ \\
\hline \multicolumn{5}{|l|}{ Team efficacy } \\
\hline PSYMOT min & $.31 * *$ & $.27^{*}$ & & \\
\hline PSYMOT range & -.13 & -.12 & $.13^{* *}$ & \\
\hline \multicolumn{5}{|l|}{ 2.Personality } \\
\hline OPEN $\max$ & --- & .14 & & \\
\hline CONSC $\max$ & --- & $.20 \dagger$ & & \\
\hline EMOTI max & --- & $.18 \dagger$ & $.24 * *$ & $.11^{*}$ \\
\hline \multicolumn{5}{|c|}{$\begin{array}{l}\text { Note. GMA }=\text { general mental ability. PSYMOT }= \\
\text { psychomotor ability. CONSC }=\text { conscientiousness. EMOTI } \\
=\text { emotional stability. OPEN }=\text { openness. Only those } \\
\text { composition variables that yielded consistently significant } \\
\text { zero-order correlations were included. Ability variables } \\
\text { were entered at Step } 1 \text {. Personality variables were entered at } \\
\text { Step 2. } \beta_{1}=\text { standardized regression coefficients at Step } 1 . \\
\beta_{2}=\text { standardized regression coefficients at Step } 2 .{ }^{\mathrm{a}} R^{2} \text { at } \\
\text { each step. }{ }^{\mathrm{b}} \mathrm{Change} \text { in } R^{2} \text { at each step. } \dagger p<.10 .{ }^{*} p<.05 . \\
{ }^{*} p<.01 .{ }^{* * *} p<.001 \text {. }\end{array}$} \\
\hline
\end{tabular}

interdependent roles and whose discretion is constrained by technological demands. However, the generalizability of the present investigation is limited by its use of a laboratory methodology and a non-field sample. Nevertheless, we recommend that future research manipulate multiple task characteristics to further investigate the extent to which task characteristics moderate the relationships between ability, personality, and team effectiveness. Considering the modest degree of association we (and previous researchers) found between the Big Five personality traits and team performance, we also suggest that future research examine the extent to which more specific aspects of the Big Five personality traits are related to team effectiveness. For example, sociability and risk-taking aspects of extraversion may be differentially related to team performance under different task characteristics. The same could be hypothesized for specific aspects of openness, such as aesthetic appreciation and enjoyment of novel problems. Furthermore, we recommend that researchers look for operationalizations other than the mean, minimum, maximum, and variance scores that might better capture the richness of different combinations of personality traits across team members. In sum, we suggest that ability warrants more consideration than personality when forming teams; however, we also acknowledge that the optimal choice of variables used to select team members and predict team effectiveness may be a function of specific teamtask requirements.

\section{REFERENCES}

Bandura, A. (1997). Self-efficacy: The exercise of control. New York: Freeman.

Barrick, M. R., Stewart, G. L., Neubert, M. J., \& Mount, M. K. (1998). Relating member ability and personality to work-team process and team effectiveness. Journal of Applied Psychology, 83, 377-391.

Cannon-Bowers, J. A., Salas, E., \& Blickensderfer, E. L. (1998). Making fine distinctions among team constructs: Worthy endeavor or "Crewel" and unusual punishment? In R. Klimoski (Chair), When is a work team a crew and does it matter? Symposium presented at the $13^{\text {th }}$ annual conference of the Society for Industrial and Organizational Psychology, Dallas, TX.

Devine, D. J., \& Philips, J. L. (2001). Do smarter teams do better? A metaanalysis of cognitive ability and team performance. Small Group Research, 32, 507-532.

Driskell, J. E., Hogan, R., \& Salas, E. (1987). Personality and group performance. In C. Hendrick (Ed.), Review of personality and social psychology (Vol. 9, pp. 91-112). Newbury Park, CA: Sage.

Goldberg, L. R. (1992). The development of markers for the Big-Five factor structure. Psychological Assessment, 4, 26-42.

Gopher, D., Weil, M., \& Bareket, T. (1994). The transfer of skill from a computer game trainer to actual flight. Human Factors, 36, 387-405.

Gopher, D., Weil, M., \& Siegel, D. (1989). Practice under changing prioritics: An approach to the training of complex skills. Acta Psychologica, 7l, 147-177.

Gully, S. M., Incalcaterra, K. A., Joshi, A., \& Beaubien, J. M. (2002). A meta-analysis of team-efficacy, potency, and performance: Interdependence and level of analysis as moderators of observed relationships. Journal of Applied Psychology, 87, 819-832.

Guzzo, R., \& Dickson, M. W. (1996). Teams in organizations: Recent research on performance and effectiveness. Annual Review of Psychology, 47, 307-338.

Hackman, J. R. (1987). The design of work teams. In J. W. Lorsch (Ed.), Handbook of organizational behavior (pp. 315-342). Englewood Cliffs, NJ: Prentice-Hall.

Hart, S. G., \& Battiste, V. (1992). Field test of a video game trainer. Proceedings of the Human Factors Society $36^{\text {th }}$ Annual Meeting, 2, 1291-1295.

Hurtz, G. M., \& Donovan, J. J. (2000). Personality and job performance: The Big Five revisited. Journal of Applied Psychology, 86, 869-879.

Mane, A. M., \& Donchin, E. (1989). The Space Fortress game. Acta Psychologica, 71, 17-22.

McGrath, J. E. (1984). Groups: Interaction and performance. Englewood Cliffs, NJ: Prentice-Hall.

McGrath, J. E., Berdahl, J. L., \& Arrow, H. (1995). Traits, expectations, culture, and clout: Dynamics of diversity in workgroups. In S. E. Jackson \& M. N. Ruderman (Eds.), Diversity in workteams: Research paradigms for changing workplace (pp. 17-45). Washington, DC: APA Press.

Neuman, G. A., \& Wright, J. (1999). Team effectiveness: Beyond skills and cognitive ability. Journal of Applied Psychology, 84, 376-389.

Raven, J. C., Court, J. H., \& Raven, J. (1985). A manual for Raven's Progressive Matrices and Vocabulary Scales. London: H. K. Lewis.

Salas, E., Bowers, C., \& Cannon-Bowers, J. A. (1995). Military team research: 10 years of progress. Military Psychology, 7, 55-75.

Steiner, I. D. (1972). Group processes and productivity. New York: Academic Press.

Tziner, A., \& Eden, J. C. (1985). Effects of crew composition on crew performance: Does the whole equal the sum of its parts? Journal of Applied Psychology, 70, 85-93. 